\title{
Male homophily in South American herpetology: one of the major processes underlying the gender gap in publications
}

\author{
Jimena Grosso $^{1,2,3, a}$, Jessica Fratani ${ }^{3, *, b}$, Gabriela Fontanarrosa ${ }^{4, c}$, Mariana Chuliver ${ }^{5, d}$, \\ Ana Sofía Duport-Bru ${ }^{3,4, e}$, Rosio Gabriela Schneider ${ }^{6,7, f}$, María Dolores Casagranda ${ }^{3, g}$, \\ Daiana Paola Ferraro ${ }^{8, h}$, Natalin Vicente ${ }^{3, i}$, María José Salica ${ }^{9, j}$, Laura Pereyra ${ }^{9, k}$, \\ Regina Gabriela Medina ${ }^{4,10,11,1}$, Carla Bessa ${ }^{12, m}$, Romina Semhan ${ }^{3, n}$, Miriam Corina Vera ${ }^{7, o}$
}

\begin{abstract}
The growing number of gender studies encourages more refined analyzes and greater conceptualization of the underlying processes of gender gap in science. In Herpetology, previous studies have described gender disparities and a scrutiny of individual interactions may help revealing the mechanisms modelling the global pattern. In this contribution we modeled a co-authorship network, a previously unexplored methodology for gender studies in this discipline, in addition to a broad and classic bibliometric analysis of the discipline. Co-authorship networks were modelled for two South American journals, because this geo-political location is considered to present the best gender balance within general scientific communities. However, we found a pattern of male preferential connections (male homophily) that marginalizes women and maintains the gender gap, at both regional and global scales. This interpretation arises from results coming from multiple analyses, such as high homophily index in collaboration networks, lower female representation in articles than expected in a non-gender biased environment, the decrease of female co-authors when the article leader is a man, and the extreme masculinization of the editorial boards. The homophilic dynamics of the publication process reveals that academic activity is pervasive to unbalanced power relationships. Personal interactions shape the collective experience, tracing back to the Feminist Theory's axiom: "the personal is political".
\end{abstract}

Keywords: authors interactions, co-authorship networks, Editorial Board, female representation, gender disparity, herpetological journals, South America.

1 - Instituto de Ciencias Marinas y Limnológicas, Universidad Austral de Chile, Valdivia, Chile

2 - Centro de Humedales Río Cruces (UACh), Valdivia, Chile

3 - Unidad Ejecutora Lillo (CONICET-FML), Tucumán, Argentina

4 - Instituto de Biodiversidad Neotropical (CONICETUNT), Tucumán, Argentina

5 - Instituto de Bio y Geociencias del NOA (CONICETUNSA), Salta, Argentina

6 - Instituto de Diversidad y Evolución Austral (CONICET), Chubut, Argentina

7 - Laboratorio de Genética Evolutiva, Instituto de Biología Subtropical (CONICET-UNaM), Misiones, Argentina

8 - División Herpetología, Museo Argentino de Ciencias Naturales "Bernardino Rivadavia" (CONICET), Buenos Aires, Argentina

9 - Instituto de Ecorregiones Andinas (CONICET-UNJu), Jujuy, Argentina

10 - Cátedra de Biología Animal, Facultad de Ciencias Naturales (UNT), Tucumán, Argentina

11 - Departamento de Ecología, Facultad de Ciencias Biológicas, Pontificia Universidad Católica de Chile,
Santiago, Chile

12 - Instituto Nacional de Limnología (CONICET-UNL), Santa Fe, Argentina

aORCID: 0000-0002-1897-6621

*Corresponding author;

e-mail: jessicafratani@gmail.com

bORCID: 0000-0002-1246-2080

cORCID: 0000-0001-5842-2263

dORCID: 0000-0001-6717-0459

e ORCID: 0000-0002-4619-7799

fORCID: 0000-0001-9245-6512

gORCID: 0000-0003-0646-0158

hORCID: 0000-0002-9579-7096

iORCID: 0000-0002-5772-3037

jORCID: 0000-0001-8864-6567

kORCID: 0000-0002-6546-4549

lORCID: 0000-0002-7846-7781

mORCID: 0000-0002-5967-3539

${ }^{\mathrm{n} O R C I D:}$ 0000-0002-7920-5003

oORCID: 0000-0003-0988-1345 


\section{Introduction}

Countless studies have documented a bias against women in science (e.g., Ceci and Williams, 2011; Handley et al., 2015; Wang and Degol, 2017; O'Brien et al., 2019; Huang et al., 2020). In 2019, UNESCO reported that women reached $29 \%$ of worldwide participation in science due to a gradual increase over the last decades, although heterogeneously through geographical locations and disciplines (Huang et al., 2020).

Argentina and Brazil stand out among the countries with the most significant progress narrowing the gender gap in recent years (Valentova et al., 2017; Elsevier Research Intelligence, 2020; Huang et al., 2020), and Life Sciences have reported a higher female participation in contrast to other scientific fields such as maths, physics, astronomy and computer science (Rossiter, 1997; Martin, 2012; McGuire et al., 2012; Bonham and Stefan, 2017; Wang and Degol, 2017; Holman et al., 2018; Salerno et al., 2019; Elsevier Research Intelligence, 2020).

Specifically in Herpetology there was a significant increase of female authors in the past decade, from $27.7 \%$ in 2010 to $34.5 \%$ in 2019 (Rock et al., 2021). Under this scenario, female herpetologists in Argentina and Brazil are supposedly subject to a double favourable condition. Nevertheless, recent analyses have shown that the increasing proportion of women in science has not led to a narrowing of the gender gap in terms of productivity, research impact, and career length (Wolfinger et al., 2009; Brooks et al., 2014; Cech and Blair-Loy, 2019; O’Brien et al., 2019; Huang et al., 2020; Rock et al., 2021).

The interactions between members of the scientific community is largely based on peer reciprocal recognition, which determines differential connections in a phenomenon called homophily (McPherson et al., 2001; Evans et al., 2011; Kegen, 2013; Fagan et al., 2018). This pattern of preferential relations is related to members' attributes, among which gender is one of the most evident (Fagan et al.,
2018). Academic articles are good indicators of research productivity and useful to discern the structure of the scientific community (Holman and Morandini, 2018; Holman et al., 2018). In this contribution we explore the publishing process, focusing on the author's interactions in Herpetology. Our main hypothesis is that in spite of a general increase in the number of women in this field, there is still a gender gap in authorship and a differential access to power positions in the publication process. We conducted a bibliometric analysis of the gender situation in the discipline and studied more closely the Argentinian and Brazilian communities, assuming they are nearly equitable in terms of gender.

\section{Materials and methods}

We collected authorship information of articles of nine herpetological journals. Journals were selected to represent different editorials groups, geographic regions, scopes and quality categories defined by the SCImago rank (SCImago, 2020), plus a non-ranked journal (i.e., Cuadernos de Herpetología; table 1). We obtained the data from the title page available on the website of each journal. Our dataset contains authorship information from the first edition to 2019 for two journals (Cuadernos de Herpetología and the South American Journal of Herpetology) and from the 2018-2019 period for the remaining journals (see the following sections for more details). We also gathered information from editorial boards members of each journal in 2019 .

The categorization as belonging to male or female was made using the first name as a proxy of gender by checking available databases (such as Gender Checker, 2020), and visual inspection of ResearchGate profiles (or similar). The individuals who could not be assigned as male or female were excluded from the analyses; however, it did not affect the overall sample size nor the relevance of the conclusions. We only portray summary statistics in this study, and the personal identity of all authors and editors included in the supporting information is masked to maintain their privacy. We are aware that the binary approach used herein for gender assignation excludes part of the community, because it might not reflect the author's self-perceived gender. We expect to overcome this limitation in future studies.

\section{Co-authorship network analysis in South American journals}

Scientific communities can be modeled as networks which intrinsically are collections of entities connected through relationships (Newman, 2004). A co-authorship network is 
Table 1. Herpetological journals sampled in this study.

\begin{tabular}{|c|c|c|c|c|}
\hline Journal & Quartile & ISSN & Publisher & Country \\
\hline Herpetologica & 1 & 180831 & $\begin{array}{l}\text { Herpetologists' League } \\
\text { Allen press }\end{array}$ & USA \\
\hline Herpetological Monographs & 1 & 7331347 & $\begin{array}{l}\text { Herpetologists' League } \\
\text { Allen press }\end{array}$ & USA \\
\hline Acta Herpetologica & 2 & $\begin{array}{l}18279635 \\
18279643\end{array}$ & Societas Herpetologica Italica & Italy \\
\hline South American Journal of Herpetology & 2 & $\begin{array}{l}1982355 X \\
18089798\end{array}$ & Brazilian Society of Herpetology & Brazil \\
\hline Phyllomedusa & 3 & 15191397 & Universidad de São Paulo & Brazil \\
\hline African Journal of Herpetology & 3 & $\begin{array}{l}21564574 \\
21533660\end{array}$ & Herpetological Association of Africa & UK \\
\hline Herpetological Bulletin & 4 & 14730928 & The British Herpetological Society & UK \\
\hline Herpetological Review & 4 & $0018084 X$ & $\begin{array}{l}\text { Society for the Study of Amphibians } \\
\text { and Reptiles }\end{array}$ & USA \\
\hline Cuadernos de Herpetología & - & $\begin{array}{c}0326-551 X \\
1852-5768\end{array}$ & $\begin{array}{l}\text { Asociación Civil Herpetológica } \\
\text { Argentina }\end{array}$ & Argentina \\
\hline
\end{tabular}

depicted by researchers connected to each other through coauthored papers (Huang et al., 2008). This operative strategy represents a methodological tool to measure aspects of complex dynamics of scientific collaboration to understand this social phenomenon (Falk-Krzesinski et al., 2011; Fagan et al., 2018).

We modeled co-authorship networks for the two journals of the oldest herpetological association in South America: Cuadernos de Herpetología (published by the Herpetological Argentine Association) and the South American Journal of Herpetology (published by the Brazilian Society of Herpetology). An adjacency matrix was calculated based on all the articles published since the first edition of each journal until 2019. The adjacency matrix defines the connectivity pattern of the community by indicating whether pairs of authors (i.e., pair of nodes) are connected by coauthorship in one or more papers. We have explicitly identified the gender of each node in the network. Based on the adjacency matrix, a non-directed and non-weighted network was constructed (for a background in network theoretic concepts, see Newman, 2001, 2004; Rasskin-Gutman and Esteve-Altava, 2014; Fagan et al., 2018, and references therein). A series of network and node parameters were calculated based on the giant component of the network, a large group of individuals who are all connected to one another by intermediate paths (Newman, 2001; see results). The giant component of the network was characterized by calculating the following parameters: (a) ratio of the number of female nodes to the total; (b) differential connections between nodes (male to male, female to female, or mixed gender); (c) network density (the number of existing connections to the maximum possible); (d) homophily coefficient (the extent to which connected nodes belong to the same gender; Newman, 2002, 2003).

Nodes were characterized by parameters of centrality and connectivity. Centrality measures capture how connected an individual node is to the network and it is often interpreted as a proxy of leadership degree in a community (Dos Santos et al., 2017). The centrality parameters assessed were: (1) degree: the number of links of a node (Csardi and Nepusz, 2006); (2) betweenness: the frequency of events in which a node is located in the shortest path between a pair of nodes (Dos Santos et al., 2017); (3) closeness: the average length of the shortest path between that particular node and all other nodes in the network (Freeman, 1979); (4) eigen-centrality: the first eigenvector of the adjacency matrix of the graph (Bonacich, 1987). Nodes with high eigen-centralities are those connected to many other nodes, which are, in turn, connected to many others (and so on). Central nodes, under this criterion, belong to centers of big cohesive sets of nodes (Csardi and Nepusz, 2006). Additionally, we have measured: (1) local transitivity: the probability that the adjacent vertices of nodes are connected (Barrat et al., 2004); (2) shortest path length: the average of the minimum distances between each pair of nodes in the network (distance is measured as the number of connections and all connections have equal length); (3) intramodular connectivity: connectivity from a given node to other nodes in its module/community; (4) participation index: uniformity in the distribution of connections to nodes that belong to other modules (Rasskin-Gutman and Esteve-Altava, 2014).

We compared node parameters within the giant component of the network between female and male nodes. The significance of the differences was calculated with KruskalWallis tests, and a post-hoc Wilcoxon pairwise comparison test was performed. The analyses were performed using igraph 1.2.5 (Csardi and Nepusz, 2006) and brainGraph 2.7.3 (Watson, 2019).

\section{Bibliometric analysis in scientific journals}

We used descriptive statistics for a general exploration of the distribution of genders in the authorship of the articles. We used Generalized Linear Models (GLMs) with quasibinomial error to explore if differences in female participation are related to the following variables: (1) taxonomic group under study (amphibians, reptiles, or both); (2) subdiscipline of study (natural history short communications, 
biogeography, conservation, ecology, ethology, genetics, methodology, morphology, and systematics); (3) publishing group (multiple-authored with mixed and same-gender groups, and single author); (4) journal quartiles (Q1-Q4 and non-ranked); and (5) authorship position (gender of the first and last author). As journals varied in the number of volumes and articles annually printed, we reduced uneven representation for each variable by randomizing and resampling articles based on the lowest category representation.

To estimate the probability of finding the resulting number of multi-authored papers with at least one woman participating, we performed 100000 simulations with the observed paper frequencies assigning the authors gender at random using the observed proportion of women in the full author pool.

\section{Editorial Board patterns}

We collected gender data for the chief and senior editors and editorial boards of each journal in 2019, except for Herpetological Bulletin, for which no information was available. We analyzed the gender composition of the editorial boards by journals and journal category. Also, we used the Jaccard index to estimate if chief editors and members of editorial boards are shared between different journals (i.e., if a same person occupies positions in two or more journals).

Co-authorship networks, bibliometric analysis, and editorial board patterns were performed in $\mathrm{R}$ version 3.6.3 ( $\mathrm{R}$ Core Team, 2020); estimations on female real versus potential participation were performed in Python (https://www. python.org/); figures were created using Inkscape (https:// inkscape.org/). Raw data is shared as supplemental files and codes are uploaded to GitHub repository (https://github. com/jessicafratani/Grosso_etal.git).

\section{Results}

\section{Co-authorship network analysis in South}

\section{American journals}

For the 461 papers published in Cuadernos de Herpetología, the number of female authors was slightly lower than male authors (46.8\%). The giant component of the network included 376 of the 595 authors (enlightened area in fig. 1A), almost half of the connections were between authors of different gender (48.9\%; fig. 1A$\mathrm{B})$, and there was no preferential connection between male or female authors (homophily coefficient $=0.012$ ). Each author was connected with about 10 other authors, without gender differences in degree. Male authors showed significantly higher betweenness, but there were no significant differences between genders in other centrality indicators. There were 16 women among the top 40 betweenness values, and the 6th place was the best-scored position reached by a woman (fig. 1C, table 2, supplementary tables S1-S2).

In the 363 papers published in the South American Journal of Herpetology, the number of female authors was lower than male authors (36.2\%). The giant component includes 478 of the 868 authors (enlightened area in fig. 1D), $53 \%$ of the connections were exclusively between men (homophily coefficient $=0.065$; fig. 1D-E). Male authors were more connected than female authors, with significantly higher centrality values. There were 12 women among the top 40 betweenness values, and the 15 th place was the best-scored position reached by a woman (fig. 1F, table 2, supplementary tables S1-S2).

In both journals, female authors presented a significantly high probability of publishing in tightly connected communities (i.e., local transitivity; table 2). Also, male and female authors did not differ in other connectivity parameters such as shortest path length, intramodular connectivity, or participation index.

\section{Bibliometric analysis in scientific journals}

Female researchers represented $30.3 \%$ of the total authors (fig. 2A, table 3). In $39.1 \%$ of the 463 analyzed articles no women participated. There were no significant differences in female participation between articles of different taxonomic groups (amphibians and reptiles; estimate $=-0.27 ; \mathrm{SE}=0.16 ; \mathrm{t}=-1.72 ; P=$ 0.08 ; fig. 2B), but differences were observed among the sub-areas of study (fig. 2C). Gender distribution was almost even in conservation articles; on the contrary, most of natural history short communications were authored by a single male author (57\%). Ecology and ethology articles had a significantly higher proportion of female authorship (36.0\% and $34.6 \%$, respectively) than biogeography, morphology, and systematics papers, which presented the 

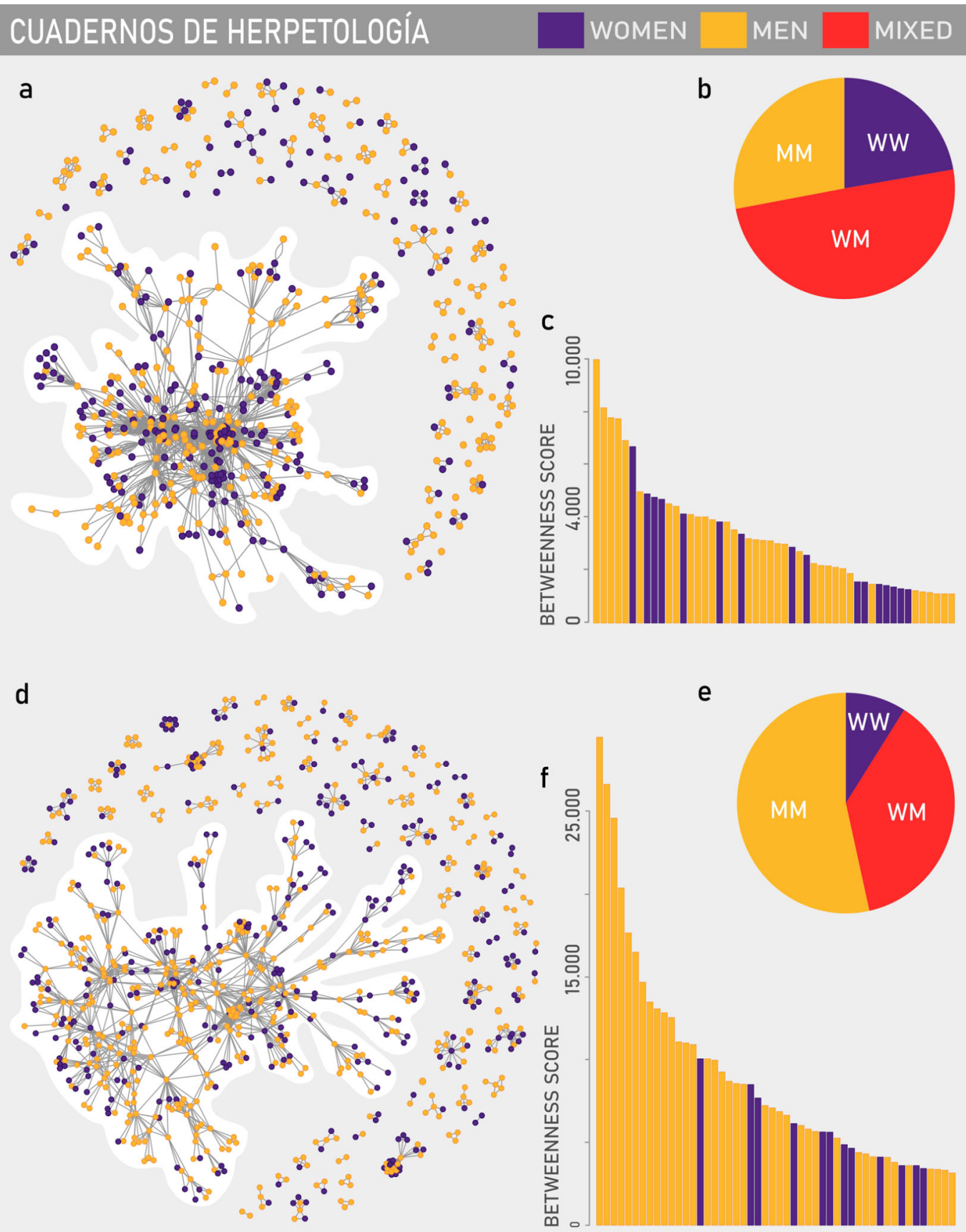

e

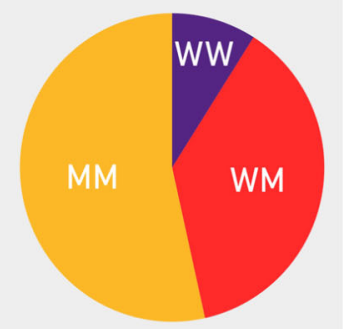

\section{SOUTH AMERICAN JOURNAL OF HERPETOLOGY}

Figure 1. Co-authorship networks of two South American herpetological journals, considering multiple-authored articles published. Each point represents an author colored by gender, and each line represents a co-authorship connection in a publication. The enlightened areas are the most connected clusters in each network. Pie-charts show the distribution of connections by gender. Barplots show the gender distribution of the first 40 higher betweenness scores. (A-C) Cuadernos de Herpetología's network of papers published between 1985 and 2019. (D-F) South American Journal of Herpetology's network of papers published between 2006 and 2019. Abbreviations: $\mathrm{MM}=$ man-man connections; $\mathrm{WM}=\mathrm{woman}-\mathrm{man}$ connections; WW = woman-woman connections. 
Table 2. Summary of Kruskal-Wallis tests of node parameters mean by gender comparisons in networks of Cuadernos de Herpetología (CHER) and South American Journal of Herpetology (SAJH).

\begin{tabular}{|c|c|c|c|c|}
\hline \multirow[t]{2}{*}{ Node parameters } & \multicolumn{2}{|l|}{ CHER } & \multicolumn{2}{|l|}{ SAJH } \\
\hline & Mean values by gender & P-values & Mean values by gender & P-values \\
\hline \multirow[t]{2}{*}{ Degree } & W: 10.69 & 0.67 & W: 4.772 & $<0.01^{* *}$ \\
\hline & M: 10.16 & & M: 7.238 & \\
\hline \multirow[t]{2}{*}{ Betweenness } & W: 345.411 & $<0.01^{* *}$ & W: 442.0799 & $<0.01^{* *}$ \\
\hline & M: 713.713 & & M: 1361.324 & \\
\hline \multirow[t]{2}{*}{ Closeness } & W: 0.0007217 & 0.76 & W: 0.000391 & $<0.01^{* *}$ \\
\hline & M: 0.0007128 & & M: 0.000418 & \\
\hline \multirow[t]{2}{*}{ Eigen-centrality } & W: 0.1147 & 0.50 & W: 0.0210 & $<0.01^{* *}$ \\
\hline & M: 0.1057 & & M: 0.0519 & \\
\hline \multirow[t]{2}{*}{ Local Transitivity } & W: 0.7492 & $<0.01^{* *}$ & W: 0.8457 & $<0.01^{* *}$ \\
\hline & M: 0.6153 & & M: 0.7450 & \\
\hline \multirow[t]{2}{*}{ Shortest path length } & $\mathrm{W}: 3.8435$ & 0.76 & W: 5.326 & 0.56 \\
\hline & M: 3.9058 & & M: 5.249 & \\
\hline \multirow[t]{2}{*}{ Intramodular connectivity } & W: 0.0158 & 0.52 & W: 0.0112 & 0.87 \\
\hline & M: -0.0139 & & M: -0.0065 & \\
\hline \multirow[t]{2}{*}{ Participation index } & W: 0.3085 & 0.82 & W: 0.0946 & 0.08 \\
\hline & M: 0.3188 & & M: 0.1213 & \\
\hline
\end{tabular}

Abbreviations: $\mathrm{W}=$ women; $\mathrm{M}=$ men.

Table 3. Summary of papers published in nine herpetological journals during 2018 and 2019.

\begin{tabular}{|c|c|c|c|c|c|c|}
\hline \multirow[t]{3}{*}{ Journal rank } & \multicolumn{3}{|c|}{ Multiple authorship } & \multicolumn{2}{|c|}{ Individual authorship } & \multirow[t]{3}{*}{ Total } \\
\hline & \multirow[t]{2}{*}{ Mixed gender } & \multicolumn{2}{|c|}{ Same gender } & \multirow[t]{2}{*}{ Men } & \multirow[t]{2}{*}{ Women } & \\
\hline & & Men & Women & & & \\
\hline Q1 & 38 & 22 & 4 & 3 & 0 & 67 \\
\hline Q2 & 49 & 14 & 1 & 1 & 0 & 65 \\
\hline Q3 & 47 & 20 & 2 & 9 & 1 & 79 \\
\hline Q4 & 95 & 51 & 5 & 50 & 14 & 215 \\
\hline CHER & 23 & 6 & 2 & 5 & 1 & 37 \\
\hline Total & 252 & 113 & 14 & 68 & 16 & 463 \\
\hline
\end{tabular}

lowest female participation (see also supplementary table S3).

Among multi-authored articles (82\% of the total), there was at least one male author in $96 \%$ of them. When at least one woman participated in an article, the average of male coauthors was 2.8; in contrast, there were on average 1.26 female co-authors in articles with at least one man. The probability that at least one woman participates in the same or lesser number of papers than the observed, using random gender assignment and the observed female proportion (0.31) was 0.07 (supplementary fig. S1). Same-gender papers represented $34 \%$ of the multi-authored articles, women-exclusive publications were a small volume (about $4 \%$ of the total of multi-authored papers) without distinction on journal quartile (fig. 2D). Women performed as first authors in $31.4 \%$ of multiauthored publications, with an increase in topquartile journals (ranging between $26 \%$ in Q4 journals and Cuadernos de Herpetología to 36\% in Q1-Q3 journals; fig. 2E-F). The gender of the first author had a significant effect on the proportion of female co-authors (estimate $=0.35 ; \mathrm{SE}=0.13 ; t=2.63 ; P<0.01$; fig. $2 \mathrm{G}$ ). Female co-authorship was $25.8 \%$ when the first author was a woman and dropped to $19.6 \%$ when the first author was a man. This trend remained the same within each quartile, however, only in Q1 journals this difference was significant (estimate $=1.3 ; \mathrm{SE}=0.4 ; t=$ 


\section{HERPETOLOGICAL JOURNALS (2018-2019) WOMEN MEN MIXED}

ALL: 463 PAPERS - 1695 AUTHORS

a

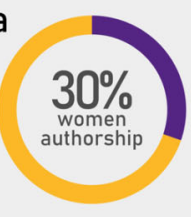

b

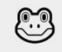

กำ

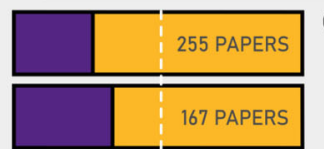

41 PAPERS

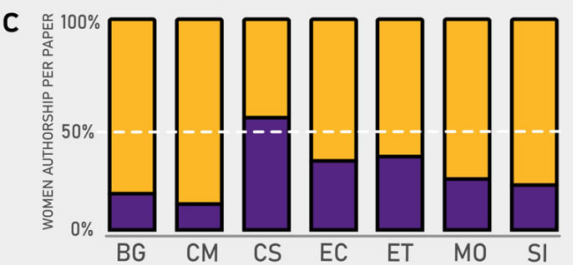

\section{MULTIPLE AUTHORS: 252 MIXED GENDER PAPERS - 127 SAME GENDER PAPERS}
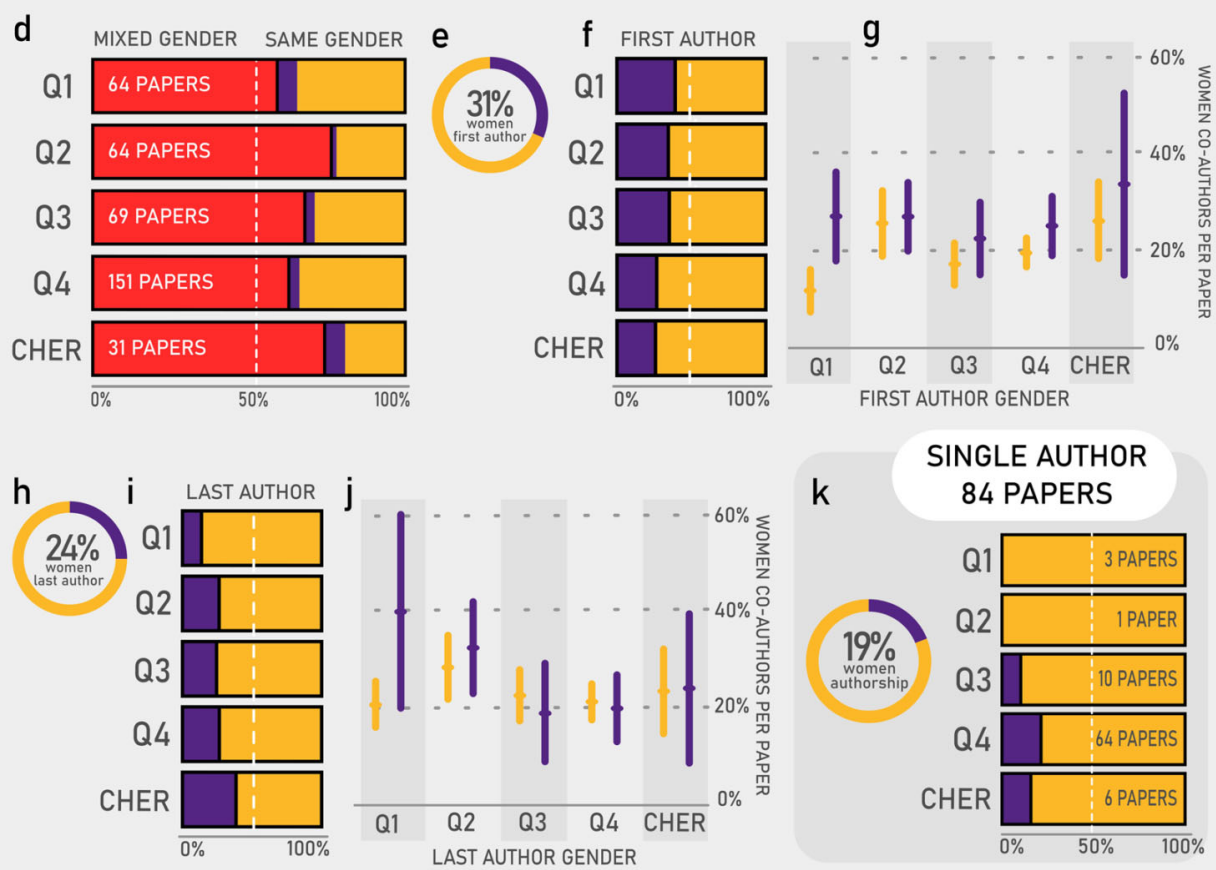

223 EDITORS: 181 MEN + 42 WOMEN
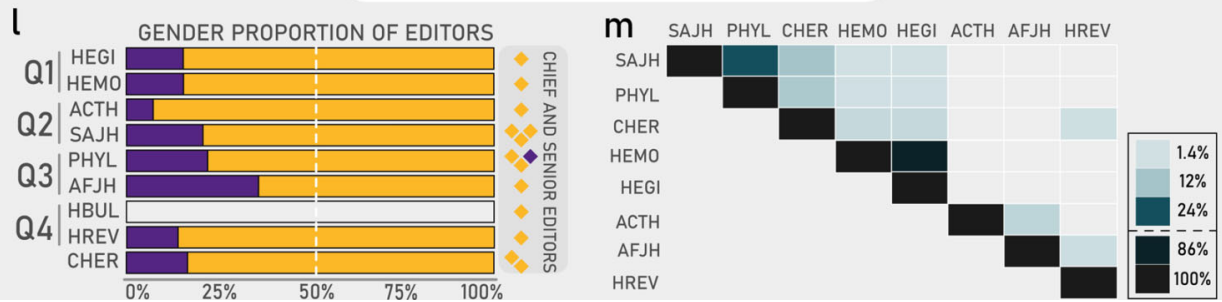

Figure 2. Bibliometric data of nine herpetological journals. (A-C) Gender ratio in papers published during 2018 and 2019 , considering different taxonomic groups and sub-areas. Multi authored papers considering the journal's qualies: (D) gender composition within publishing groups, and (E-J) gender participation in protagonic roles and its effect on the proportion of female co-authors. Single authored papers: $(\mathrm{K})$ gender distribution on average and discriminated by journal's qualies. Editorial Boards by journals in 2019: (L) gender proportion within each journal, and (M) percentage of similarity between members of different journals. Abbreviations: $\mathrm{ACTH}=$ Acta Herpetologica; $\mathrm{AFJH}=$ African Journal of Herpetology; $\mathrm{BG}=$ Biogeography $; \mathrm{CHER}=$ Cuadernos de Herpetología $; \mathrm{CM}=$ Communication $; \mathrm{CS}=$ Conservation $; \mathrm{EC}=$ Ecology; $\mathrm{ET}=$ Ethology; HBUL = Herpetological Bulletin; HEGI = Herpetologica; HEMO = Herpetological Monographs; HREV = Herpetological Review; $\mathrm{MO}=$ Morphology; $\mathrm{PHYL}=$ Phyllomedusa; SAJH = South American Journal of Herpetology;

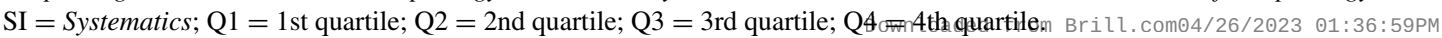


3.231; $P<0.001)$. Women were last-authors in $24.4 \%$ of total multi-authored articles, with a higher percentage in bottom-quartile journals (33\% in Q4 and $\mathrm{CH}$ and 22\% in Q1-Q3 journals; fig. 2H-I). The last author's gender had no statistically significant effect on female co-authorship among journals nor quality categories (this may be related to the low number of female last authors in the sample); however, a trend to a higher female participation per paper was observed when the last author was a woman in Q1 and Q2 journals (fig. 2J).

Among the single-authored articles, most of them were published in bottom-quartiles journals, and $19 \%$ of them were written by a woman (16 papers; fig. $2 \mathrm{~K}$ ). Men published alone $81 \%$ of the time (68 papers), principally in natural history, short communications, and ecology and biogeography articles.

\section{Chair and Editorial Board patterns}

In 2019, the editor-in-chief and senior editors of the nine journals analyzed (fig. 2L, table 1) were men except for one woman who performed as senior editor in Phyllomedusa journal. Editorial boards were composed of 223 editors, with a female representation of $23 \%$ (ranging from $7 \%$ to $36 \%$ in different journals). The editorial boards of Phyllomedusa and South American Journal of Herpetology (both Brazilian journals) shared $24 \%$ of their members, while the editorial board of Herpetological Monographs and Herpetologica (both Q1 journals) presented $86 \%$ of their members in common (fig. $2 \mathrm{M}$ ).

\section{Discussion}

There is a documented tendency to publish with authors of the same gender across Life Sciences (Holman and Morandin, 2018; Elsevier Research Intelligence, 2020). Even under the relative favourable condition in Argentinian and Brazilian Herpetology our results showed that gender homophily is one of the main mechanisms modulating the interaction structure in
Herpetology. Positive men's homophily was detected in the South American Journal of Herpetology network model and male homophily was also detected in international publications and in journal editorial boards.

In the networks of South American Journal of Herpetology and Cuadernos de Herpetología there is a tendency of both male and female authors to establish connection routes that pass through a male node (i.e., men's nodes tend to have higher betweenness scores). While Cuadernos de Herpetología presents a trend to gender equality, the South American Journal of Herpetology showed a deeper gender asymmetry with significant higher values for male network homophily and all centrality parameters. The two journals have a similar scope but differ on their quartiles: Cuadernos de Herpetolgía is an unranked journal while South American Journal of Herpetology is ranked as quartile 2 (SCImago, 2020). The impact factor of a journal is not a measure of the quality of individual scientists' research articles (Cislak et al., 2018), but it represents the prestige of the journal and implies a broader public outreach (Pernerger, 2010). Our results indicate a rising male homophily among coauthors of the better categorized journal, hindering the possibility of a woman to access environments perceived as prestigious.

Among herpetologists publishing in the South American journals, the probability that two authors with a common collaborator write a paper together is above $60 \%$, increasing over $70 \%$ if the common collaborator is a woman. This suggests that the Herpetological community in South America established highly cohesive publishing groups, which explains the more local and restricted range of influence of female researchers against a more widespread influence of men. Previous studies claim that gender difference in interpersonal interaction strategies is caused by different styles of social network construction, in which girls tend to evolve in small homogeneous groups (Shrum et al., 1998; Helmer et al., 2017). Explaining the relative 
insularization of women might not be straightforward. We hypothesize that at least three causes (with possible interactions among them) may lead to this result: women prefer to work within the same group and do not expand their connections, women are not invited to collaborate with members outside their work groups, and women face difficulties to collaborate outside their main work group when they intend to do so.

Women are more represented in South American $36 \%$ and $47 \%$ of the total number of authors in SAJH and CHER, respectively) than in international journals (30\%). During 2018 and 2019 women were absent in $39 \%$ of the international articles, while at least one man was present in almost all multi-authored articles (94\%) and published alone four times more often than women. A similar trend based on a more comprehensive dataset of herpetological articles showed a general predominance of male authors and a higher number of single authored papers published by men (Rock et al., 2021). Although these numbers show a male dominated scenario, we wondered if the low participation of women in publishing groups is related to a small number of female authors as a baseline population or if there are other underlying processes. We found that with random gender assignment, the probability of having the observed participation of women or less is 0.07 . In other words, in $93 \%$ of the cases the simulation resulted in a better scenario for women than portrayed by the real data. The depicted gender bias can be explained by a male to male preference for publishing, a pattern that has recurrently emerged in our analyses.

A recent analysis found that women are less represented in studies involving herpetological taxa perceived as dangerous such as Crocodylia (Rock et al., 2021). We were not able to find a differential pattern of female participation between articles of different taxonomic groups, maybe because we used categories with lower taxonomic resolution (i.e., amphibia, reptilia). We did find that female authors surpassed the overall average of participation in articles concerning ecology, ethology and conservation, but are underrepresented in articles of subdisciplines such as morphology, systematics, biogeography and natural history short communications. Although we were not able to identify if this trend is related to differences in social interactions, to historical background, or to the nature of the work such as type of field work; further analyses could clarify it.

Previous reports for Herpetology and other scientific areas found that women are overrepresented as first author and underrepresented as last author (Martin, 2012; West et al., 2013; Fox et al., 2018; Salerno et al., 2019; Rock et al., 2021). Our analyses showed that leading roles (first and last authors) in herpetological publications are occupied by a woman about one fourth of the time. Journals with higher quartiles have on average the highest female participation as first authors and the lowest female participation as last authors. There is a shift of this tendency in the lower quartile journals, with a higher proportion of female last authors. These numbers seem to depict an active recruitment of women during their early stages of their careers publishing in high impact journals, but a probable shorter permanence in activity than their male counterparts. Consequently, there are less women in leadership positions within research groups as well as available for mentoring. In a more optimistic scenario, the gradual increase of women participation over the last years will fill that gap in the near future. Further analyses in the next decade may give us a better diagnosis of the situation.

Women in leadership positions pull up other female researchers and generate a positive effect on gender balance, as was also described for other disciplines and fields of biology (Sardelis and Drew, 2016; Bonham and Stefan, 2017; Potvin et al., 2018; Salerno et al., 2019; Rock et al., 2021). We found that when a woman occupies one of the central roles in herpetological articles (i.e., first or last author), the 
number of female co-authors increases. However, these women in leadership positions are few and scattered in a male homophilic system. Previous researches demonstrated that when the influence of these driver women is reduced, the systems quickly returns to their previous gender-biased state (Helmer et al., 2017; Maas et al., 2020). It should also be noted that in this male dominated context, publications with female majority could end up being passed over or less cited due to unconscious negative bias (Larivière et al., 2013; Helmer et al., 2017).

Journal's editorial boards play a crucial role in science, supervising the quality and type of publications and influencing the course of research (Zsindely et al., 1982; Mauleón et al., 2013; Cho et al., 2014). Members of editorial boards are commonly peer-selected, according to their experience and prestige (Crane, 1967; Merton et al., 1977; Pearson et al., 2006). Editorial boards of herpetological journals are strongly masculinized and present some overlap of their members among journals (fig. 2L-M). The alarming low number of women in editorial boards concerns not only herpetological journals but also a wide range of STEM journals (Cho et al., 2014; Fox et al., 2016; Salerno et al., 2019; Liévano-Latorre et al., 2020). These numbers misrepresent the gender diversity of the scientific community and it might negatively influence the manuscript evaluation process and women's participation in published research (Metz and Harzing, 2009; Mauleón et al., 2013; Cho et al., 2014). Previous studies showed that editors of both genders have a homophilic tendency to appoint reviewers, reinforcing the inbreeding homophily of the peerreview system (Helmer et al., 2017). Although most herpetological journals analyzed in this paper promote gender equity in authorship, we found no formal regulation of this aspect on editorial boards. Balancing the representativity of women in editorial boards should be included in editorial policies (Cho et al., 2014). In line with this, after the approval of the Gender Equity Protocol of the AHA in 2019, six new women editors have been incorporated into its journal (Cuadernos de Herpetología). This rising female proportion-from $14 \%$ to $35 \%$-evidences the relevance of policy making to cope with gender inequality.

In summary, we revealed three main aspects of the gender situation in herpetology. Firstly, female participation in South America is greater than in general scientific communities. This result is similar to previous findings for the broad scientific community (Elsevier Research Intelligence, 2020). Further studies that include the social and economic situation of the countries in the last decades are needed to comprehend this pattern. Secondly, we identified a large percentage of women publishing in high impact journals during their early career stages, but their participation declines as last author, probably reflecting a shorter permanence in activity. This result is in agreement with previous analyses including different scientific disciplines (e.g., Huang et al., 2020), and represents a useful diagnosis to design institutional policies to promote the permanency of women in Herpetology. Lastly, we found that male homophily is contributing to a strong inertial pattern of a community historically rooted in a male dominated environment (Rock et al., 2021). One shocking example is the composition of the editorial boards, even more worrying because of the key position they hold in the publishing process. As noticed, reversing this pattern of gender inequality is not ensured by merely increasing the total number of women in scientific fields, but it may be addressed by designing policies that consider the historical and inherited processes operating under gender imbalance and identifying the groups in which these policies need to be focused.

Acknowledgements. We are very grateful to Dr. Andrea Torricella (Instituto de Humanidades y Ciencias Sociales - CONICET) for contributing with ideas and discussions regarding the topics of our project, and to the two anonymus reviewers who kindly improved the early version of this manuscript. We also want to especially thank all essential workers whose effort allowed us to continue our academic 
work within the context of the global lockdown in which the writing of this manuscript was performed. Financial support was received from CONICYT Concurso FONDECYT de Postdoctorado $2020 \mathrm{~N}^{\circ} 3200490$ (JG) and grants from Agencia Nacional de Promoción de la Investigación, el Desarrollo Tecnológico y la Innovación to the mentioned authors: PICT 2015-820 (DPF), PICT 2017-2437 (JG), PIP 0389, and PICT 2016-2772 (GF, JF, MCV).

Supplementary material. Supplementary material is available online at:

https://doi.org/10.6084/m9.figshare. 14915640

\section{References}

Barrat, A., Barthelemy, M., Pastor-Satorras, R., Vespignani, A. (2004): The architecture of complex weighted networks. Proc. Natl. Acad. Sci. 101: 3747-3752.

Bonacich, P. (1987): Power and centrality: a family of measures. Am. J. Sociol. 92: 1170-1182.

Bonham, K.S., Stefan, M.I. (2017): Women are underrepresented in computational biology: an analysis of the scholarly literature in biology, computer science and computational biology. PloS One 13: e1005134.

Brooks, C., Fenton, E.M., Walker, J.T. (2014): Gender and the evaluation of research. Res. Policy 43: 990-1001.

Cech, E.A., Blair-Loy, M. (2019): The changing career trajectories of new parents in STEM. Proc. Natl. Acad. Sci. 116: 4182-4187.

Ceci, S.J., Williams, W.M. (2011): Understanding current causes of women's underrepresentation in science. Proc. Natl. Acad. Sci. 108: 3157-3162.

Cho, A.H., Johnson, S.A., Schuman, C.E., Adler, J.M., Gonzalez, O., Graves, S.J., et al. (2014): Women are underrepresented on the editorial boards of journals in environmental biology and natural resource management. PeerJ 2: e542.

Cislak, A., Formanowicz, M., Saguy, T. (2018): Bias against research on gender bias. Scientometrics 115: 189-200.

Costas, R., Bordons, M. (2011): Do age and professional rank influence the order of authorship in scientific publications? Some evidence from a micro-level perspective. Scientometrics 88: 145-161.

Crane, D. (1967): The gatekeepers of science: some factors affecting the selection of articles for scientific journals. Am. Sociol. 2: 195-201.

Csardi, G., Nepusz, T. (2006): The igraph software package for complex network research. InterJournal, Complex Syst. 1695: 1-9.

Dos Santos, D.A., Fratani, J., Ponssa, M.L., Abdala, V. (2017): Network architecture associated with the highly specialized hindlimb of frogs. PloS One 12: e0177819.

Elsevier Research Intelligence (2020): The Researcher Journey Through a Gender Lens: a Global Examination of Research Participation, Career Progression and Perceptions. Elsevier Connect, Netherlands.
Evans, T.S., Lambiotte, R., Panzarasa, P. (2011): Community structure and patterns of scientific collaboration in business and management. Scientometrics 89: 381-396.

Fagan, J., Eddens, K.S., Dolly, J., Vanderford, N.L., Weiss, H., Levens, J.S. (2018): Assessing research collaboration through co-authorship network analysis. J. Res. Adm 49: 76-99.

Falk-Krzesinski, H.J., Contractor, N., Fiore, S.M., Hall, K.L., Kane, C., Keyton, J., et al. (2011): Mapping a research agenda for the science of team science. Res. Eval. 20: 145-158.

Fox, C.W., Burns, C.S., Muncy, A.D., Meyer, J.A. (2016): Gender differences in patterns of authorship do not affect peer review outcomes at an ecology journal. Funct. Ecol. 30: 126-139.

Fox, C.W., Ritchey, J.P., Paine, C.E.T. (2018): Patterns of authorship in ecology and evolution: first, last, and corresponding authorship vary with gender and geography. Ecol. Evol. 8: 11492-11507.

Freeman, L.C. (1979): Centrality in social networks: conceptual clarification. Soc. Netw. 1: 215-239.

Gender Checker (2020): Retrieved from https:// genderchecker.com. Accessed December 15, 2019.

Handley, I.M., Brown, E.R., Moss-Racusin, C.A., Smith, J.L. (2015): Quality of evidence revealing subtle gender biases in science is in the eye of the beholder. Proc. Natl. Acad. Sci. 112: 13201-13206.

Helmer, M., Schottdorf, M., Neef, A., Battaglia, D. (2017): Gender bias in scholarly peer review. Elife 6: e21718.

Holman, L., Morandin, C. (2019): Researchers collaborate with same-gendered colleagues more often than expected across the life sciences. PLoS One 14: e0216128.

Holman, L., Stuart-Fox, D., Hauser, C.E. (2018): The gender gap in science: how long until women are equally represented? PLoS One 16: e2004956.

Huang, J., Zhuang, Z., Li, J., Giles, C.L. (2008): Collaboration over time: characterizing and modeling network evolution. In: Proceedings of the 2008 International Conference on Web Search and Data Mining, pp. 107116.

Huang, J., Gates, A.J., Sinatra, R., Barabasi, A.L. (2020): Historical comparison of gender inequality in scientific careers across countries and disciplines. Proc. Natl. Acad. Sci. 117: 4609-4616.

Hwang, S.S., Song, H.H., Baik, J.H., Jung, S.L., Park, S.H., Choi, K.H., et al. (2003): Researcher contributions and fulfillment of ICMJE authorship criteria: analysis of author contribution lists in research articles with multiple authors published in Radiology. Radiology 226: 16-23.

Kegen, N.V. (2013): Science networks in cutting-edge research institutions: gender homophily and embeddedness in formal and informal networks. Procedia Soc. Behav. Sci. 79: 62-81.

Larivière, V., Ni, C., Gingras, Y., Cronin, B., Sugimoto, C.R. (2013): Bibliometrics: global gender disparities in science. Nature News 504: 211-213. 
Lariviere, V., Desrochers, N., Macaluso, B., Mongeon, P., Paul-Hus, A., Sugimoto, C.R. (2016): Contributorship and division of labor in knowledge production. Soc. Stud. Sci. 46: 417-435.

Liévano-Latorre, L.F., da Silva, R.A., Vieira, R.R.S., Resende, F.M., Borges, F.J.A., et al. (2020): Pervasive gender bias in editorial boards of biodiversity conservation journals. Biol. Conserv. 251: 108767.

Maas, B., Pakeman, R.J., Godet, L., Smith, L., Devictor, V., Primack, R. (2021): Women and Global South strikingly underrepresented among top-publishing ecologists. Conservation Letters: e12797.

Martin, L.J. (2012): Where are the women in ecology? Front. Ecol. Environ. 10: 177-178.

Mauleón, E., Hillán, L., Moreno, L., Gómez, I., Bordons, M. (2013): Assessing gender balance among journal authors and editorial board members. Scientometrics 95: 87114.

McGuire, K.L., Primack, R.B., Losos, E.C. (2012): Dramatic improvements and persistent challenges for women ecologists. BioScience 62: 189-196.

McPherson, M., Smith-Lovin, L., Cook, J.M. (2001): Birds of a feather: homophily in social networks. Annu. Rev. Sociol. 27: 415-444.

Merton, R., Storer, N.W., Miguez, N.A. (1977): La sociología de la ciencia: investigaciones teóricas y empíricas. Alianza Universidad, Madrid.

Metz, I., Harzing, A.W. (2009): Gender diversity in editorial boards of management journals. Acad. Manag. Learn. Educ. 8: 540-557.

Newman, M.E.J. (2001): The structure of scientific collaboration networks. Proc. Natl. Acad. Sci. 98: 404-409.

Newman, M.E.J. (2002): Assortative mixing in networks. Phys. Rev. Lett. 89: 208701.

Newman, M.E.J. (2003): Mixing patterns in networks. Phys. Rev. E 67: 026126.

Newman, M.E.J. (2004): Coauthorship networks and patterns of scientific collaboration. Proc. Natl. Acad. Sci. 101: 5200-5205.

O’Brien, K.R., Holmgren, M., Fitzsimmons, T., Crane, M.E., Maxwell, P., Head, B. (2019): What is gender equality in science? Trends Ecol. Evol. 34: 395-3599.

Pearson, C.H., Mullen, R.W., Thomason, W.E., Phillips, S.B. (2006): Associate editor's role in helping authors and upholding journal standards. Agron. J. 98: 417-422.

Perneger, T.V. (2010): Citation analysis of identical consensus statements revealed journal-related bias. J. Clin. Epidemiol. 63: 660-664.

Potvin, D.A., Burdfield-Steel, E., Potvin, J.M., Heap, S.M. (2018): Diversity begets diversity: a global perspective on gender equality in scientific society leadership. PLoS One 13: 1-14.

R Core Team (2020): R: a Language and Environment for Statistical Computing. R Foundation for Statistical Computing, Vienna, Austria. Retrieved from https:// www.R-project.org/.
Rasskin-Gutman, D., Esteve-Altava, B. (2014): Connecting the dots: anatomical network analysis in morphological EvoDevo. Biol. Theory 9: 178-193.

Rock, K.N., Barnes, I.N., Deyski, M.S., Glynn, K.A., Milstead, B.N., Rottenborn, M.E., et al. (2021): Quantifying the gender gap in authorship in herpetology. Herpetologica 77: 1-13.

Rossiter, M. (1997): Which science? Which women? Osiris 12: $169-185$.

Salerno, P.E., Páez-Vacas, M., Guayasamin, J.M., Stynoski, J.L. (2019): Male principal investigators (almost) don't publish with women in ecology and zoology. PLoS One 14: e0218598.

Sardelis, S., Drew, J.A. (2016): Not "pulling up the ladder": women who organize conference symposia provide greater opportunities for women to speak at conservation conferences. PLoS One 11: 1-20.

SCImago (n.d.). SJR - SCImago Journal \& Country Rank. Retrieved from http://www.scimagojr.com. Accessed 15 January 2020.

Shrum, W., Cheek, N.H., Hunter, S.M. (1988): Friendship in school: gender and racial homophily. Sociol. Educ. 61: 227-239.

Tscharntke, T., Hochberg, M.E., Rand, T.A., Resh, V.H., Krauss, J. (2007): Author sequence and credit for contributions in multiauthored publications. PloS One 5: e18.

UNESCO (2019): Retrieved from http://uis.unesco.org/ sites/default/files/documents/fs55-women-in-science2019-en.pdf. Accessed 10 June 2019.

Valentova, J.V., Otta, E., Silva, M.L., McElligott, A.G. (2017): Underrepresentation of women in the senior levels of Brazilian science. PeerJ 5: e4000.

Wang, M.T., Degol, J.L. (2017): Gender gap in Science, Technology, Engineering, and Mathematics (STEM): current knowledge, implications for practice, policy, and future directions. Educ. Psychol. Rev. 29: 119-140.

Watson, C.G. (2019): brainGraph: Graph theory analysis of brain MRI data, $\mathrm{R}$ package version 2.7.3. Retrieved from https://cran.r-project.org/web/packages/ brainGraph/index.html. Accessed 5 June 2019.

West, J.D., Jacquet, J., King, M.M., Correll, S.J., Bergstrom, C.T. (2013): The role of gender in scholarly authorship. PloS One 8: e66212.

Wolfinger, N.H., Mason, M.A., Goulden, M. (2009): Stay in the game: gender, family formation and alternative trajectories in the academic life course. Soc. Forces $\mathbf{8 7}$ : 1591-1621.

Zsindely, S., Schubert, A., Braun, T. (1982): Editorial gatekeeping patterns in international science journals. A new science indicator. Scientometrics 4: 57-68.

Submitted: April 12, 2021. Final revision received: May 13, 2021. Accepted: June 20, 2021.

Associate Editor: Karin Tamar. 